\title{
Pre-test e-learning module Goedkoop Gezonde Voeding
}

\author{
C.W.H. Knobel \\ Maastricht University \\ c.knobel@student.maastrichtuniversity.nl
}

\section{Samenvatting}

Introductie. Voeding is een belangrijk aspect voor de gezondheid en kwaliteit van leven van mensen. Echter hebben mensen met een lage sociaaleconomische status vaker een ongezond voedingspatroon, wat kan leiden tot verschillende leefstijl gerelateerde aandoeningen. Door middel van de interventie Goedkoop Gezonde Voeding wordt hier geprobeerd op in te spelen. Deze interventie wordt gegeven door diëtisten, die op voorhand een e-learning module moeten volgen. Om het effect van de e-learning te vergroten en daarmee de gegeven trainingen van de interventie te verbeteren, kan gebruik gemaakt worden van een pre-test, het op voorhand testen zodat aanpassingen nog mogelijk zijn voordat geïmplementeerd wordt. Methoden. In totaal werden zeven interviews met diëtisten gehouden terwijl de e-learning werd doorlopen door de diëtiste. Om te garanderen dat ieder onderdeel (achtergrondinformatie, filmpjes, werkbladen en toepassingsopdrachten) werd geëvalueerd door ten minste twee diëtisten, werd een verdeling gemaakt van de onderdelen over de diëtisten. Bij ieder onderdeel van de e-learning werden vragen vooraf, tijdens en na doorlopen van het desbetreffende onderdeel gesteld. Van de audio-opnamen werden transcripten gemaakt en deze werden geanalyseerd met behulp van Nvivo. Resultaten. De e-learning en de vormgeving hiervan worden goed gewaardeerd. Door de meerderheid van de diëtisten werd aangegeven dat de e-learning toepasbaar is op de huidige werkwijze van de diëtiste, voornamelijk voor diëtisten met een eigen praktijk. Onderdelen die minder goed gewaardeerd werden, waren de filmpjes en de onderwerpen die tot de basiskennis behoren. Daarnaast moet volgens diëtisten multiculturaliteit meer geïntegreerd worden binnen de e-learning. Conclusie. Over het algemeen wordt de e-learning module Goedkoop Gezonde Voeding goed gewaardeerd door diëtisten. Implicaties zijn om onderwerpen te verwijderen of te verminderen die tot de basiskennis van een diëtiste behoren. De e-learning kan online worden gezet na een aantal kleine aanpassingen. Hierdoor zal de e-learning beter aansluiten bij de doelgroep 
en zal later gebruik geoptimaliseerd worden. Dit zal de resultaten van de daadwerkelijke interventie Goedkoop Gezonde Voeding ten goede komen.

\section{Kernbegrippen}

Pre-testen, e-learning module, lage sociaaleconomische status, gezonde voeding, diëtisten, cognitive interviewing.

\section{Introductie}

Voeding is een belangrijk aspect voor de gezondheid en kwaliteit van leven van mensen. Een gezond voedingspatroon kan bijdragen aan een goede gezondheid, maar een ongezond voedingspatroon kan echter bijdragen aan een slechte gezondheid en kan leiden tot verschillende leefstijl gerelateerde aandoeningen, zoals kanker, hart- en vaatziekten en diabetes (World Health Organisation, 2015). Het gevolg is een vermindering van de kwaliteit van leven en een toename van de ziektelast (Ministerie van Volksgezondheid, Welzijn en Sport, 2008). Vooral de inname van verzadigde vetten en de consumptie van te weinig groente en fruit wordt geassocieerd met het risico op chronische ziekten (WHO, 2003). De groente- en fruitinname van specifieke groepen is echter ver onder de norm. Vooral mensen met een lagere sociaaleconomische status (SES) hebben vaker een ongezond voedingspatroon (Hulshof, Brussaard, Kruizinga, Telman, \& Löwik, 2003). Deze groep eet minder groente en fruit en heeft een verhoogde inname van verzadigde vetten. Als gevolg van het ongezonde eetpatroon is deze groep gevoeliger voor het krijgen van leefstijl gerelateerde aandoeningen en heeft een lagere levensverwachting dan de hogere sociaaleconomisch klassen (Oudshoorn et al., 2002).

Aan de hand van gezondheidsbevordering kan ingespeeld worden op de leefstijl van mensen en kan geprobeerd worden om deze te verbeteren. Gezondheidsbevordering is een overkoepelde term voor activiteiten om mensen te stimuleren zich op een vrijwillige basis gezonder te willen en kunnen gedragen (Brug, van Assema, \& Lechner, 2012). Het doel is om mensen in staat te stellen meer controle te krijgen over de determinanten van gezondheid en daarmee hun gezondheid te verbeteren (WHO, 2003).

Het onderzoek dat hier wordt beschreven, is gebaseerd op de interventie Goedkoop Gezonde Voeding, vroeger ook bekend als Goede Voeding hoeft niet veel te kosten (Assema, Steenbakkers, Rademaker \& Brug, 2005). Goedkoop Gezonde Voeding is recent grootschalig herzien in samenwerking met diëtisten, de GGZ Zuid-Limburg en de Universiteit Maastricht. In de interventie ligt de focus op mensen met een klein inkomen en 
hoe zij toch gezond kunnen eten met een kleiner budget. De twee bijeenkomsten worden gegeven door gecertificeerde diëtisten. Zij ontvangen deze certificatie na het doorlopen van een e-learning module die gevolgd kan worden via de website van Goedkoop Gezonde Voeding.

E-learning is een relatief nieuwe manier voor het vergroten van kennis. Door het aanbieden van e-learning kan de stof afgestemd worden op de doelgroep om te voldoen aan persoonlijke leerdoelen. Wanneer een interventie aansluit bij een individu is de kans op positieve resultaten een stuk groter dan wanneer geen gebruik wordt gemaakt van e-learning (Wantland, Portillo, Holzemer, Slaughter \& McGhee, 2004). Het voornaamste voordeel van e-learning is het leeraanbod dat kan worden gevolgd wanneer het de cursist uitkomt (Ruiz, Mintzer, \& Leipzig, 2006). E-learning heeft een toegevoegde waarde op de effecten van gezondheidsbevorderingsprogramma's (Ruiter, Fransen, Molleman, van der Velden \& Engels, 2015). Daarnaast is de kennis over een bepaald onderwerp groter na het volgen van een e-learning. Dit verbetert de implementatie van de interventie (van de Steeg, IJkema, Wagner \& Langelaan, 2015).

Het doel van het thesisonderzoek is om te bepalen hoe de e-learning module voor Goedkoop Gezonde Voeding gewaardeerd wordt door diëtisten. Daarnaast wordt gekeken hoe de afzonderlijke onderdelen worden gewaardeerd, in hoeverre de leerstof toepasbaar is op de huidige werkwijze van diëtisten en of er onderdelen missen of verbeterd kunnen worden.

\section{Methoden}

Design en procedure

$\mathrm{Er}$ is gebruik gemaakt van een pre-test onderzoek, het systematisch voorleggen van een concept aan de doelgroep. De meerwaarde van pre-testen binnen de uiteindelijke doelgroep was het vinden van mogelijkheden voor verbetering van de e-learning. Op deze manier werd de kwaliteit van de interventie bewaakt, zodat bijstellen van de e-learning module mogelijk werd (Tones \& Green, 2010).

Voorafgaande aan de werving werd door de onderzoeker een verdeling gemaakt waarin per diëtiste verschillende onderdelen van de e-learning module werden uitgekozen om zo de gehele module te dekken en een zo representatief mogelijke pre-test te krijgen. De verdeling is zo gemaakt dat iedere diëtiste achtergrondinformatie te lezen kreeg, een filmpje en werkbladen heeft gezien en een toepassingsopdracht kon maken. Deze 
vormden de kernelementen van de e-learning module waardoor feedback van alle deelnemers aan de pre-test van groot belang was.

\section{Werving van de onderzoekspopulatie}

De diëtisten zijn geworven via de Nederlandse Vereniging van Diëtisten (NVD) en de Diëtisten Coöperatie Nederland (DCN). Leden van beide verenigingen zijn benaderd per e-mail met uitleg over het onderzoek en de vraag om hier aan deel te nemen. Hierbij zijn voornamelijk diëtisten gekozen met een eigen praktijk. Bij hen werd de kans het grootst geacht dat onderdelen van de e-learning module mee konden worden genomen in de huidige werkwijze. In totaal zijn 46 diëtistenpraktijken per e-mail benaderd en hebben zeven diëtisten deelgenomen aan het onderzoek.

\section{Meetinstrument}

Voor de verzameling van de data zijn face-to-face interviews gehouden bij de diëtisten thuis of op het werk. Hierbij werd gebruik gemaakt van een semigestructureerde vragenlijst. De vragenlijst is gebaseerd op de techniek 'cognitive interviewing'. Met deze techniek wordt gefocust op de cognitieve processen die respondenten gebruiken bij het beantwoorden van survey vragen en kunnen vragen zo opgesteld worden dat deze processen meegenomen worden (Willis, 2013).

Vooraf aan het interview werden achtergrondkenmerken nagevraagd waaronder naam, leeftijd, organisatie waar de diëtiste werkzaam is, ervaring met groepsvoorlichting, bekendheid met Goedkoop Gezonde Voeding en eerdere ervaringen met e-learning modules. Vervolgens werden de specifieke onderdelen nagevraagd. Dit betroffen vragen over hoe de achtergrondinformatie, het filmpje, de werkbladen en de toepassingsopdracht over het desbetreffende onderwerp werden gewaardeerd. Deze vragen werden onderverdeeld in positieve punten en verbeterpunten van het subonderdeel. Daarnaast werd de toepbasbaarheid op de huidige werkwijze nagevraagd. Na ieder onderdeel kreeg de diëtiste de mogelijkheid om overige feedback te geven over de doorgenomen stof. Tot slot werd het interview afgesloten met algemene vragen over de e-learning waaronder de algemene toepasbaarheid van de e-learning op de huidige werkwijze, verbeterpunten van de e-learning module en de algemene indruk van de opmaak van de e-learning.

\section{Analyse}

Van de geluidopnames werden transcripten gemaakt. Aan de hand van NVivo 10 zijn de transcripten van de interviews geanalyseerd. Op voorhand werden case nodes en tree 
nodes aangemaakt per onderdeel van de vragenlijst om de transcripten te organiseren een aan te vullen waar nodig. Bekendheid met Goedkoop Gezonde Voeding, e-learning, toepasbaarheid op huidige werkwijze, verbeterpunten, prijs en opmaak van de e-learning behoorden tot de case nodes. Tree nodes werden gebruikt per onderdeel van de e-learning module en werden verder onderverdeeld in waardering achtergrondinformatie, waardering filmpje, waardering werkbladen, waardering toepassingsopdracht en toepasbaarheid op huidige werkwijze. Deze nodes werden verder onderverdeeld in positieve punten en verbeterpunten van dat specifieke onderdeel. Daarnaast zijn free nodes toegepast om gegevens buiten de vooraf opgestelde onderwerpen te markeren en mee te nemen in de analyse. Deze waren 'tekstuele opmerkingen', 'opdrachten voor deelnemers', 'onduidelijkheden vanuit diëtiste' en 'algemene opmerkingen'. Per node werd een samenvatting gemaakt die verwerkt werden in de resultaten.

\section{Resultaten}

De e-learning module werd in het geheel benoemd als een goed initiatief met veel potentie voor positieve resultaten. Enkele diëtisten gaven aan dat het thema van de module steeds meer een hot item wordt en daarmee ook goede start is voor het geven van de trainingen. De opmaak van de e-learning module werd door alle diëtisten heel netjes en fris ervaren. Hierbij werd aangegeven de site overzichtelijk en toegankelijk te vinden. De e-learning module werd door alle diëtisten duidelijk en gebruiksvriendelijk bevonden. Twee van de zeven diëtisten hadden bij sommige onderdelen de neiging om over de tips heen te lezen. Een meerderheid van de diëtisten $(n=6)$ gaf aan dat de e-learning module 'zeker wel' toepasbaar was op de huidige werkwijze op een vijfpuntsschaal van 'zeker niet' tot 'zeker wel'. Eén diëtiste gaf hierbij 'mogelijk wel' aan. Daarnaast kwam naar voren dat bepaalde onderwerpen werden besproken die in de opleiding al uitgebreid aan bod zijn geweest. Deze onderwerpen waren wel toepasbaar, maar het was geen nieuwe informatie. Voor de diëtisten werkzaam bij een organisatie was de e-learning minder toepasbaar, aangezien zij andere werkzaamheden verrichten dan de diëtisten met een eigen praktijk.

De introductie van de module werd door alle diëtisten goed gewaardeerd. De tekst was helder, duidelijk en heel volledig beschreven. Doordat de introductie was opgedeeld in verschillende onderdelen en bepaalde onderwerpen konden worden uitgeklapt, werd het als erg overzichtelijk waargenomen. De meerderheid van de diëtisten $(n=4)$ gaf aan dat zij vruchtensap en fruit uit blik of pot niet zouden stimuleren door de grotere hoeveelheden suikers die in deze producten zitten. De diëtisten zagen liever dat het verschil tussen de producten duidelijk uitgelegd werd, mocht de tip gegeven worden. 
Er werden in de achtergrondinformatie goede en praktische tips gegeven die door de diëtisten als kernpunten van de tekst werden ervaren $(n=7)$. De blokken met informatie aan het begin van het onderdeel $(n=5)$ en de tekstfragmenten van eerder gegeven trainingen $(n=4)$ waren ook positieve punten. Deze zorgde voor een overzichtelijk geheel van dat specifieke onderdeel en een duidelijk beeld van hoe de trainingen eruit zouden zien. Een minder goed punt van de achtergrondinformatie was dat er soms te veel op onderwerpen in werd gegaan die tot de basiskennis van de diëtisten behoorden $(n=5)$. Zij zagen liever onderwerpen die nieuw waren, zoals het geven van groepslessen en het feedback geven en ontvangen. Deze onderwerpen werden beter gewaardeerd en waren interessanter om te lezen.

De vijf filmpjes werden door de diëtisten verschillend gewaardeerd. Een positief punt dat werd genoemd, was dat een filmpje een leuke afwisseling is. Een andere diëtiste vult aan dat het goed is dat er vanuit verschillende invalshoeken wordt gesproken en dat er nieuwe argumenten worden aangedragen. De andere diëtisten gaven aan het filmpje geen toevoeging te vinden $(n=4)$. Het idee van een filmpje sprak wel aan, maar qua inhoud waren de filmpjes geen toevoeging.

De werkbladen werden over het algemeen goed gewaardeerd en als volledig beschouwd $(n=7)$. Vooral dat de werkbladen in pdf's werden weergegeven, werd als positief punt ervaren. Doordat ook de informatie hierin werd weergegeven, was de tekst eenvoudig terug te vinden en eenvoudig uit te printen en mee te nemen $(n=6)$. Als verbeterpunt gaven meerdere diëtisten aan de tips die in de tekst genoemd werden ook in een pdf te zetten om het overzicht te vergroten $(n=6)$. Hetzelfde kwam naar voren voor praktische tips en kernaspecten die tijdens de cursus gegeven worden. Deze pdf's kunnen dan meegenomen worden door de deelnemers en informatie kan op deze manier eenvoudig terug worden gezocht.

De toepassingsopdrachten na ieder onderdeel werden door de diëtisten $(n=7)$ als toevoeging ervaren. Volgens de diëtisten kon zo actief nagedacht worden over hoe invulling kon worden gegeven aan de training wanneer men deze zelf zou geven $(n=6)$. Sommige toepassingsopdrachten werden als te lang of te eenvoudig ervaren.

Tot slot, werden algemene suggesties voor de e-learning gegeven. Een suggestie die werd aangedragen door enkele diëtisten was om informatie over de voedselbank op te nemen in de module $(n=3)$. De voedselbank kan een belangrijk onderdeel zijn van mensen met 
een lage SES en daarom belangrijk om de toekomstige cursusleiders hier mee bekend te maken. Daarnaast bevatten de pakketten van de voedselbank niet altijd gezonde voedingsproducten, omdat zij afhankelijk zijn van giften. Dit was volgens de diëtisten een belangrijke uitdaging om bewust van te zijn en de deelnemers toch gezonder kunnen laten eten. Een andere diëtiste $(n=1)$ had graag een stukje uitleg opgenomen gezien in de module over de schijf van vijf. Deze was onderdeel van de folders die deelnemers mee naar huis konden nemen, maar werd nergens in de module of de training besproken. Voor de volledigheid van de module zou het goed zijn om deze te bespreken in de training. Een laatste diëtiste gaf aan om met apps te werken $(n=1)$. De module hoort vernieuwend te zijn. Dit was voor de diëtiste een belangrijk communicatiekanaal naar de deelnemers toe en een mogelijkheid voor deelnemers om extra informatie op te zoeken.

Tabel 1. Meeste voorkomende inhoudelijke suggesties

Inhoudelijke suggesties

Meer onderwerpen die nieuw zijn voor diëtisten. Niet teveel in gaan op het voedingsaspect, dat tot de basiskennis van diëtisten behoort. $(n=7)$

Meer multiculturele onderwerpen in de andere onderdelen verweven. $(n=5)$

Belangrijkste gegevens en praktische tips op pdf zetten om voor deelnemers mee naar huis te nemen $(n=6)$

Een onderdeel over de voedselbank toevoegen $(n=3)$

\section{Discussie/conclusie}

De e-learning module wordt over het algemeen goed gewaardeerd door diëtisten. Een aantal factoren die dit kunnen verklaren, zijn de complexiteit, comptabiliteit en het relatief voordeel van de e-learning, die behoren tot de kenmerken van de innovatie (Rogers, 2003). Wanneer de complexiteit van een innovatie, in dit geval een e-learning, kleiner wordt, zal een e-learning waarschijnlijk eerder gebruikt worden door diëtisten. Hetzelfde geldt voor wanneer de comptabiliteit en het relatief voordeel groter worden. Dit zijn de mate waarin een e-learning past binnen de bestaande manier van werken en de mate waarin de e-learning als beter wordt ervaren dan de huidige werkwijze. De complexiteit van deze e-learning is erg laag, waar de comptabiliteit en het relatief voordeel groot zijn voor diëtisten. In eerder onderzoek wordt de 'perceived usefulness' als een van de kenmerken genoemd die de tevredenheid over een e-learning kan beïnvloeden en dus is het belangrijk voor de implementatie van een e-learning om dit kenmerk zo groot mogelijk te maken (Sun, Tsai, Finger, Chen \& Yeh, 2008). Dit houdt in dat de gebruiker een 
e-learning eerder zal gebruiken wanneer deze ervaart dat de e-learning een toevoegende waarde heeft. Een implicatie voor later gebruik of onderzoek is om rekening te houden met deze verschillende factoren. Een eerdergenoemde suggestie is om meer onderwerpen op te nemen waar diëtisten nog weinig ervaring mee hebben. De 'perceived usefulness' zal op deze manier vergroot worden (Sun et al., 2008). Dit komt ook terug in de specifieke onderdelen 'achtergrondinformatie', 'filmpjes' en 'toepassingsopdrachten.

Per specifiek onderdeel zijn ook verklaringen te geven die het potentieel gebruik van de e-learning kunnen beïnvloeden. Zo werd bij de introductie aangegeven dat deze erg eenvoudig in gebruik is. Dit heeft betrekking op de term 'perceived ease of use' dat naar voren komt in het artikel van Sun et al. (2008). Naarmate het gebruik van een e-learning eenvoudiger wordt, zal deze ook eerder gebruikt worden.

De e-learning module wordt door alle diëtisten toepasbaar beschouwd op de huidige werkwijze. Hierbij is wel een duidelijk onderscheid te zien in de diëtisten die een zelfstandige praktijk hebben en diëtisten die voor een organisatie werken. Voor diëtisten die niet zelfstandig werken is de module minder toepasbaar op de huidige werkwijze. Diëtisten met een zelfstandige praktijk verrichten vaak andere werkzaamheden dan de diëtisten werkzaam bij een organisatie. Doordat de leerstof meer van toepassing is voor diëtisten met een eigen praktijk, zal voor hen de 'perceived usefulness' ook groter zijn en zijn zij eerder geneigd om de e-learning later te gebruiken (Pituch \& Lee, 2006).

\section{Limitaties en sterke punten}

Een limitatie van dit onderzoek is dat er maar een selectieve response is geweest op de verzonden mails. De onderzoekspopulatie is hierdoor vrij klein en de onderdelen van de e-learning konden niet door alle diëtisten beoordeeld worden. Dit komt ook als limitatie naar voren in recent onderzoek (Skye, Wimsatt, Master-Hunter \& Locke, 2011). Daarin wordt echter ook beschreven dat dit voor kwalitatief onderzoek geen groot probleem hoeft te zijn. Een oorzaak van de selectieve response kan zijn dat diëtisten die positief tegenover e-learning staan of al werkervaring hebben met mensen met een lage SES eerder zullen deelnemen aan het onderzoek dan diëtisten die niets met e-learning hebben of waarbij het onderwerp niet aanspreekt. Daarnaast kunnen diëtisten werkzaam bij een organisatie anders tegen een e-learning aankijken en onderdelen lager waarderen dan diëtisten met een eigen praktijk. Voor hen is de module minder toepasbaar op hun huidige werkwijze en dus is het voor hen ook moeilijker in te schatten in welke mate de onderdelen volstaan voor het geven van de trainingen. Voor deze pre-test van de e-learning is dit echter geen groot 
probleem, aangezien mee is genomen welke beoordelingen van welke diëtiste kwam. Beoordelingen van diëtisten met een zelfstandige praktijk zijn zwaarder meegenomen dan beoordelingen van diëtisten werkzaam bij een organisatie.

Een sterk punt van dit onderzoek is dat het vernieuwend is. Er zijn nog maar weinig pretesten gedaan van e-learning modules. Daarnaast is een positief punt dat de interviews bij de diëtisten thuis of op het werk worden gehouden. Op deze manier kost het voor de diëtisten zo min mogelijk tijd en is de belasting van deelname aan het onderzoek een stuk lager. Dit kan voor de diëtisten een reden zijn om toch deel te nemen. Een ander punt is dat er gebruik is gemaakt van face-to-face interviews aan de hand van cognitive interviewing. Hierdoor is er weinig sprake van informatiebias en komt meer informatie naar voren dan met bijvoorbeeld een vragenlijst. Tot slot is een sterk punt dat aanbevelingen uit dit onderzoek meegenomen kunnen worden voordat de e-learning online gaat. Dit benadrukt het belang van pre-testen om de slagingskans in praktijk te vergroten. Dit komt overeen met een implicatie benoemd in het onderzoek van Yoong et al. (2015). Hierin wordt beschreven dat het essentieel is om een e-learning te testen voordat deze online wordt gezet.

Het pre-testen van een e-learning module voordat deze online wordt gezet en in de praktijk wordt gebruikt, is van groot belang. Uit de pre-test die gedaan wordt bij de doelgroep kunnen aanbevelingen naar voren komen die meegenomen kunnen worden voor het verbeteren van de e-learning. Hierdoor zal de e-learning beter aansluiten bij de doelgroep en zal later gebruik geoptimaliseerd worden. Dit zal de resultaten van de daadwerkelijke interventie Goedkoop Gezonde Voeding ten goede komen.

\section{Rol van de student}

Chantal Knobel heeft in een thesisgroep onder begeleiding van Kathelijne Bessems gewerkt aan haar thesisonderzoek. De onderzoeksvragen zijn in overleg met de begeleidster geformuleerd, alsmede de uitwerking van het design. De uitvoering van het onderzoek, het verwerken van de resultaten en de discussie zijn geheel door de student uitgevoerd. 


\section{References}

1. Assema, P. V., Steenbakkers, M., Rademaker, C., \& Brug, J. (2005). The impact of a nutrition education intervention on main meal quality and fruit intake in people with financial problems. Journal of human nutrition and dietetics, 18(3), 205-212.

2. Brug, J., van Assema, P., \& Lechner, L. (2012). Gezondheidsvoorlichting en gedragsverandering. Een planmatige aanpak: Uitgeverij Van Gorcum.

3. Hulshof, K. F., Brussaard, J. H., Kruizinga, A. G., Telman, J., \& Löwik, M. R. (2003). Socio-economic status, dietary intake and 1oy trends: the Dutch National Food Consumption Survey. European Journal of Clinical Nutrition, 57(1), 128-137.

4. Ministerie van Volksgezondheid, Welzijn en Sport. (2008). Gezonde voeding van begin tot eind. Nota voeding en gezondheid. Geraadpleegd op 25 maart 2015, via http://www.rijksoverheid.nl/documenten-enpublicaties/brochures/2010/12/o8/gezonde-voeding-van-begin-tot-eind-nota-voeding-en-gezondheid.html

5. Oudshoorn, K., Perenboom, R., Mulder, Y., Hoeymans, N., Deeg, D., Portrait, F. R., et al. (2002). Gezonde levensverwachting naar sociaal-economische status. TNO Preventie en Gezondheid, Divisie Volksgezondheid.

6. Pituch, K. A., \& Lee, Y. K. (2006). The influence of system characteristics on e-learning use. Computers \& Education, 47(2), 222-244.

7. Rogers, E. M. (2003). Diffusion of innovations. New York: Simon and Schuster.

8. Ruiter, E. L., Fransen, G. A., Molleman, G. R., van der Velden, K., \& Engels, R. C. (2015). The effectiveness of a web-based Dutch parenting program to prevent overweight in children 9-13 years of age: study protocol for a two-armed cluster randomized controlled trial. BMC public health, 15(1), 148.

9. Ruiz, J. G., Mintzer, M. J., \& Leipzig, R. M. (2006). The impact of e-learning in medical education. Academic medicine, 81(3), 207-212.

10. Skye, E. P., Wimsatt, L. A., Master-Hunter, T. A., \& Locke, A. B. (2011). Developing online learning modules in a family medicine residency. Family Medicine-Kansas City, 43(3), 185.

11. Steeg, L. van de, IJkema, R., Wagner, C., \& Langelaan, M. (2015). The effect of an e-learning course on nursing staff's knowledge of delirium: a before-and-after study. BMC medical education, 15(1), 12.

12. Sun, P. C., Tsai, R. J., Finger, G., Chen, Y.Y., \& Yeh, D. (2008). What drives a successful e- Learning? An empirical investigation of the critical factors influencing learner satisfaction. Computers \& education, 50(4), 11831202.

13. Tones, K., \& Green, J. (2010). Health promotion: planning and strategies. London: Sage.

14. Wantland, D. J., Portillo, C. J., Holzemer, W. L., Slaughter, R., \& McGhee, E. M. (2004). The effectiveness of Web-based vs. non-Web-based interventions: a meta-analysis of behavioral change outcomes. Journal of medical Internet research, 6(4).

15. Willis, G. B. (2013). Cognitive Interviewing: A "How To" Guide. 1999. Paper presented at the Short course presented at the meeting of the American Statistical Association. 
16. World Health Organisation. (2003). Diet, nutrition and the prevention of chronic diseases. WHO technical report series (916), 1-60.

17. World Health Organisation. (2015). Noncommunicable diseases. Fact sheet. Geraadpleegd 5 mei 2015, via http://www.who.int/mediacentre/factsheets/fs355/en/

18. Yoong, S. L., Williams, C. M., Finch, M., Wyse, R., Jones, J., Freund, M., et al. (2015). Childcare Service Centers' Preferences and Intentions to Use a Web-Based Program to Implement Healthy Eating and Physical Activity Policies and Practices: A Cross-Sectional Study. Journal of Medical Internet Research, 17(5), 108. 